\title{
AN ACOUSTIC ANALYSIS OF CONTEMPORARY VOWELS OF THE STANDARD SLOVENIAN LANGUAGE
}

\author{
${ }^{1}$ Center for PersonKommunikation \\ Institute of Electronic Systems \\ Aalborg University \\ 9220 Aalborg, Denmark
}

Bojan Petek $^{1,2}$, Rastislav Šuštaršič ${ }^{3}$, and Smiljana Komar ${ }^{3}$

\begin{abstract}
Slovenian language is among the richest Slavic languages in view of the number of dialects. More than 40 dialects in seven dialect groups can be found on a territory of about $21,000 \mathrm{~km}^{2}$ and population of 2 million. Given the richness of influencing factors on the Standard Slovenian language we decided to undertake an acoustic analysis of its contemporary vowel system. Results on vowel formant frequencies and durations using the Kay Elemetrics Computerized Speech Lab are presented for the monophthongs uttered by educated speakers of Standard Slovenian. The emphasis of research reported in this paper is on a comparative analysis of durations of the Slovenian vowels. The measurements support the basic division of vowels into long stressed and short unstressed ones, while the further subdivision of stressed vowels into long and short only seems to be valid for one particular vowel, i.e., the open central vowel /a/.
\end{abstract}

\section{INTRODUCTION}

The Slovenian dialect system consists of 7 major dialectal regions [5], i.e., Koroška (Carinthia), Primorska, Rovtarska, Gorenjska (Upper Carniola), Dolenjska (Lower Carniola), Štajerska (Styria), and Panonska (Pannonia). Historically, parts of the Slovenian dialect system attracted considerable attention of researchers (e.g., [10]). Recently, several thorough studies of the Slovenian dialect system have been published, e.g., by Logar [5] on the Slovenian dialect system as a whole, by Steenwijk [7] on the Slovenian dialect of Resia, San Giorgio, and by Zorko [11] on the dialectal portrait of the Drava valley. Unfortunately, not so many attempts [6] have been made to conduct an updated description of Standard Slovenian using a Sonagraph $[8,9]$. Our work contributes to this topic by using a computerized methodology in analyzing the data.

The next section of the paper describes the methodology adopted in this work. Then a brief overview of the Slovenian vowel system is given which details measurements of the first three formant frequencies and an acoustic representation of the 8 Slovenian monophthongs. Section 4 of the paper discusses the analysis of vowel durations and compares the results with the previously reported work of Bezlaj [3] and Srebot-Rejec [6].

\footnotetext{
${ }^{2}$ Visiting researcher from the University of Ljubljana, Slovenia and postdoctoral scholar of the Slovenian Science Foundation.
}

\author{
${ }^{3}$ Department of Germanic Languages and Literatures \\ Faculty of Arts \\ University of Ljubljana \\ 1000 Ljubljana, Slovenia
}

\section{METHODOLOGY}

Two types of text scripts were prepared for the analysis of the Standard Slovenian vowels. The first was a short word set (about 4 $\mathrm{min} / \mathrm{speaker}$ ), containing isolated words and (up to four) words in a short sentence. This set included 96 tokens. Words have been selected with a goal to obtain controlled minimal pair- and syllable environments. Due to morphological and phonological rules of Standard Slovenian this criterion had to be relaxed several times at the expense of obtaining monosyllabic/polysyllabic word pairs. The second script was a paragraph of continuous speech (about 1 $\mathrm{min} / \mathrm{speaker}$ ), which was read only by two speakers (one male and one female).

In the present study, only the former word set was used in the experimental work. Two male and two female educated speakers were recorded on a portable Digital Audio Tape recorder (Sony TCDD3) using an AKG cardioid condensor microphone with a linear frequency characteristic $(20 \mathrm{~Hz}-20 \mathrm{kHz} \pm 1 \mathrm{~dB}$, microphone noise level $\leq 18 \mathrm{dBA}$ ). The recorded material was later analyzed using a Kay Elemetrics Computerized Speech Lab (CSL, Model 4300B, software version 5.03). Formant trajectories within the manually segmented monophthongs of three speakers (two male and one female) were computed using the CSL. The sample values of the first three formants were taken at the middle of the formant trajectory contour. Vowel quality analysis included the study of height (modelled by the frequency of formant one) and backness (modelled by the difference between frequencies of formant two and formant one) [4]. Vowel durations were calculated from the manually positioned boundaries in order to enable a comparative analysis with previously published results.

\section{VOWEL QUALITY IN STANDARD SLOVENIAN}

The vowel system in Standard Slovenian is described as consisting of long and short /i, a, u/, long /e:, $\varepsilon$ :, o:, o:/, and short / $\varepsilon, \mathrm{o}$, ə/ [1, 2]. Table 1 summarizes the classification of the Slovenian monophthongs by combining the length and their distribution in stressed or unstressed syllables.

All vowels occur in stressed and unstressed syllables, but /e/ and /o/ are used in unstressed positions in a few words only, e.g., the auxil- 


\begin{tabular}{|c|c|c|}
\hline \hline \multicolumn{2}{|c|}{ STRESSED } & UNSTRESSED \\
\hline i:, e:, $\varepsilon:$, a:, ॰:, o:, u: & i, $\varepsilon, \mathrm{a}$, ,, $\mathrm{u}$, ə & $\mathrm{i}, \varepsilon, \mathrm{a}$, ,, $\mathrm{u}$, ə \\
\hline LONG & \multicolumn{2}{|c|}{ SHORT } \\
\hline \hline
\end{tabular}

Table 1: Traditional classification of monophthongs in Standard Slovenian.

iary bo 'will' in bo ŠEL 'he will GO' and the adverb že in že DVAkrat 'already TWICE' (Table 2). The unstressed vowels are phonologically always short.

\begin{tabular}{|c|c|c|c|}
\hline \multicolumn{4}{|r|}{ LONG } \\
\hline i: & mit & /mi:t/ & 'myth' \\
\hline e: & med & /me: $\mathrm{t} /$ & 'honey' \\
\hline$\varepsilon:$ & peta & $/ \mathrm{p} \varepsilon: \mathrm{ta} /$ & 'heel' \\
\hline a: & mat & /ma:t/ & 'mate' (in chess) \\
\hline o: & pot & /ps:t/ & 'sweat' \\
\hline o: & pot & /po:t/ & 'path’ \\
\hline u: & pust & /pu:st/ & 'dull' \\
\hline \multicolumn{4}{|r|}{ SHORT } \\
\hline $\mathrm{i}$ & bik & /bik/ & 'bull' \\
\hline$\varepsilon$ & rep & $/ \mathrm{r} \varepsilon \mathrm{p} /$ & 'tail' \\
\hline $\mathrm{a}$ & rak & $/ \mathrm{rak} /$ & 'cancer' \\
\hline 0 & post & /post/ & 'fast' (act or period of fasting) \\
\hline $\mathrm{u}$ & kup & /kup/ & 'pile' \\
\hline ə & pes & /pos/ & 'dog' \\
\hline
\end{tabular}

Table 2: An example list of monophthongs for Standard Slovenian.

The approximants / $/$ and /j/ form closing diphthongs with preceding vowels when they are followed by consonants and in the word-final position. The labio-dental / $/$ / in these positions becomes a bilabial second element of the diphthong, i.e., close $/ \mathrm{u} /$, and $/ \mathrm{j} /$ becomes close /i/ (Table 3).

\begin{tabular}{|c|lll|}
\hline \hline \multicolumn{4}{|c|}{ SLOVENIAN DIPHTHONGS } \\
\hline ei & glej & /glei/ & 'look' (imp.) \\
ai & daj & /dai/ & 'give' (imp.) \\
ui & tuj & /tui/ & 'foreign' \\
oi & tvoj & /tvoi/ & 'your' (masc.) \\
oi & boj & /boi/ & 'battle' \\
iu & pil & /piu/ & 'drank' \\
eu & pel & /peu/ & 'sang' \\
cu & lev & $/$ leu/ & 'lion' \\
au & pav & /pau/ & 'peacock' \\
ou & pol & /pou/ & 'half' \\
əu & topel & /to:pau/ & 'warm' \\
\hline \hline
\end{tabular}

Table 3: A list of diphthongs used in Standard Slovenian.

Slovenian diphthongs, however, are generally considered as allophonic combinations of vowels and approximants, occuring only in those words and word-forms in which they are not followed by vowels. Thus, for example, the pronoun tvoj 'yours' is analyzed as consisting of four phonemes (/tvo:j/) because it is only in this particular word-form that $/ \mathrm{j} /$ is in the final position (as compared to $t v o j a$, tvoji, tvoje 'yours', i.e., different forms of the word 'your' in different genders, cases, and numbers).

\subsection{Formant Frequency Analysis}

Three informants (two male and one female) were selected for measurements of formant frequencies of the monophthongs listed in Table 2. Since the number of tokens per monophthong was not large enough to enable a robust statistics of formants, the data was pooled by disregarding the long/short division of the monophthongs. Given that such an assumption is only valid when there are no differences in sound quality between the short and long vowels, an experiment using much larger data set needs to be conducted. Nevertheless, formant trajectories of the 8 monophthongs within the manually positioned boundaries were extracted using the Kay Elemetrics CSL and analyzed later using MATLAB. The measurements were checked for consistency in estimation of formant frequencies and the ones with obvious measurement errors were discarded from further analysis. As pointed out in Section 2, the values of the first three formant frequencies were sampled at the middle point of the formant trajectory within each token.

Table 4 summarizes the measurements for the first three formants, averaged accross speakers within each vowel class. Furthermore, Figure 1 depicts an approximate position of the bulk of the tongue in the oral cavity during the production of the Slovenian monophthongs.

\begin{tabular}{|c|c|c|c|}
\hline \hline VOWEL & F1 & F2 & F3 \\
\hline $\mathrm{i}$ & 301 & 2,250 & 2,886 \\
$\mathrm{e}$ & 387 & 1,916 & 2,792 \\
$\varepsilon$ & 528 & 1,730 & 2,113 \\
$\mathrm{a}$ & 735 & 1,362 & 1,991 \\
$\mathrm{o}$ & 577 & 973 & 2,140 \\
$\mathrm{o}$ & 414 & 733 & 2,100 \\
$\mathrm{u}$ & 317 & 621 & 2,063 \\
$\partial$ & 456 & 1,370 & 2,121 \\
\hline \hline
\end{tabular}

Table 4: Average values of the formant frequencies of vowels in standard Slovenian obtained by the Kay Elemetrics Computerized Speech Lab (data was pooled across 3 speakers, in $\mathrm{Hz}$ ).

\section{VOWEL LENGTH IN STANDARD SLOVENIAN}

The duration analysis is based on a recording of one female (MŠ, an actress, "Slovensko Mladinsko Gledališče", Ljubljana) and one male (RŠ, lecturer, University of Ljubljana) speakers, both from the Slovenian capital, Ljubljana.

\subsection{Traditional Classification}

Slovenian vowels are traditionally classified into long and short stressed vowels, and short unstressed vowels. The mid-close /e/ and /o/ are always considered as stressed and long, while the Slovenian schwa is always regarded as a short vowel, regardless of whether it is stressed or unstressed (see Table 1). 


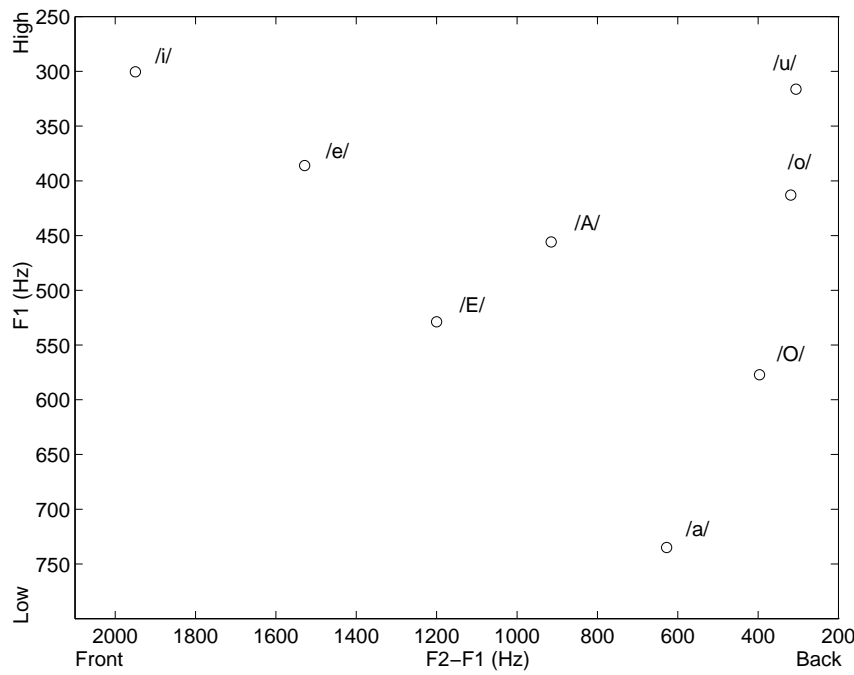

Figure 1: The relative auditory qualities of the Slovenian vowels. Symbols /E/, /O/, /A/ denote the monophthongs $\varepsilon$, ว, ə, respectively.

The short stressed /i,a,u/ and / $\varepsilon, \mathrm{J} /$ generally occur in closed syllables and contrast with their long counterparts in those word-forms in which the vowels occur in open syllables (e.g., sit|si-ta 'full' (not hungry), krap $\mid k r a-p a$ 'carp', kup $\mid k u-p a$ 'pile', rep|re-pa 'tail', post|po-sta 'fast'). As for the short stressed/i,a,u/, there is strong evidence that they were not only quantitatively, but also qualitatively considerably different in the past, and weakened in some dialects to /ə/ (e.g., sit /sət/, krap /krəp/, kup /kəp/). Such pronunciation is still used in dialects today but is not considered as standard.

\subsection{Acoustic Analysis by F. Bezlaj and T. Srebot-Rejec}

The first Slovenian linguist to study the duration of vowels in Standard Slovenian instrumentally, was F. Bezlaj in 1939 [3]. For the long stressed vowels, among which he included a long schwa in open-syllable position (e.g., in ste-za/stə:za/ 'path'), he obtained the values, depending on the types of words in which the vowels were measured, as summarized in Table 5.

\begin{tabular}{|c|c|c|c|}
\hline \hline \multicolumn{2}{|c|}{ LONG STRESSED } & \multicolumn{2}{c|}{ SHORT STRESSED } \\
\hline i: & 113 & $\mathrm{i}$ & 84 \\
$\mathrm{e}:$ & 164 & & \\
$\varepsilon:$ & 129 & $\varepsilon$ & 131 \\
$\mathrm{a}:$ & 172 & $\mathrm{a}$ & 141 \\
$\mathrm{o}:$ & 140 & $\mathrm{\jmath}$ & 131 \\
$\mathrm{o}:$ & 168 & & \\
$\mathrm{u}:$ & 123 & $\mathrm{u}$ & 89 \\
ə: & 103 & ə & 113 \\
\hline \hline
\end{tabular}

Table 5: Durations (in miliseconds) of stressed vowels in the Standard Slovenian (after Bezlaj [3]).

From the Table 5 it can be observed that the long vowels in general are longer than the short ones, but with one exception, i.e., the

\begin{tabular}{|c|c|c|c|c|c|}
\hline \hline \multicolumn{3}{|c|}{ VowEL } & \multicolumn{3}{c|}{ SPEAKER } \\
\cline { 4 - 6 } \multicolumn{2}{|c|}{} & & 1 & 2 & 3 \\
\hline bik & $/$ bik/ & 'bull' & 68 & 60 & 71 \\
lik & /li:k/ & 'shape' & 79 & 60 & 64 \\
\hline rak & $/$ /rak/ & 'cancer' & 68 & 106 & 98 \\
trak & $/$ /ra:k/ & 'belt' & 106 & 106 & 83 \\
\hline pod & $/$ pot/ & 'floor' & 143 & 91 & 98 \\
dob & $/$ do:p/ & 'eras' (gen. pl.) & 174 & 106 & 75 \\
\hline kup & $/$ kup/ & 'pile' & 45 & 45 & 53 \\
kup & /ku:p/ & 'buy' (noun) & 68 & 60 & 45 \\
\hline \hline
\end{tabular}

Table 6: Durations (in miliseconds) of some of the stressed of vowels in Standard Slovenian (after Srebot-Rejec [6]).

schwa, which is, surprisingly, longer in close- than in open-syllable position (the words compared were ste-za/stə:za/ and pes /pəs/).

For the unstressed vowels, Bezlaj gives a general statement summarizing the results obtained by instrumental measurements, i.e., that these vowels are approximately 50\%-65\% shorter than the long stressed vowels.

Almost 50 years later T. Srebot-Rejec studied word accent and vowel duration in Standard Slovenian [6]. On the basis of her measurements, she arrived to the conclusion that vowel length is phonologically no longer relevant, since her informants, speakers of Standard Slovenian, generally made no relevant distinctions between the long and short stressed vowels in pairs of words, for which such a distinction would be expected. In several cases, the expected short vowel is actually longer than the expected long vowel. Table 6 shows some of her results obtained on the basis of pronunciation of three different speakers.

\subsection{Present Acoustic Analysis Results}

In spite of the results of the analysis above, Slovenian linguists continue to make the traditional distinction between the long and short stressed vowels. We believe, however, that the phonological distinction between the few potentialy minimal pairs such as, e.g., kup|kup, /kup/|/ku:p/, 'pile'|'buy' (noun), or daj mi KAKŠEN primer|KAKŠEN primer mi daš, /kakšən/|/ka:kšən/, 'give me AN example'|'WHAT example do you give me', does not reflect the actual current pronunciation, and that such words are completely neutralized in the pronunciation of speakers of Standard Slovenian. On the other hand, it is still unclear whether such a distinction exists when one considers the prevailing occurrence of short stressed vowels in closed syllables vs. their long counterparts in open syllables.

The aim of our analysis was, therefore, to measure the duration of stressed short and long vowels, as well as that of unstressed vowels, both in open and closed syllables, in order to work out general ratios between the three types of vowels in Slovenian.

Experimental results on the average durations of long stressed, short stressed, and unstressed Standard Slovenian monophthongs are summarized in Table 7. 


\begin{tabular}{|c|c|c|}
\hline \hline \multicolumn{3}{|c|}{ LONG STRESSED VOWELS } \\
\hline \multirow{2}{*}{$\mathrm{i}:$} & Speaker RS & Speaker MŠ \\
\cline { 2 - 3 } $\mathrm{e}:$ & 109 & 107 \\
$\varepsilon:$ & 171 & 159 \\
$\mathrm{a}:$ & 164 & 148 \\
$\mathrm{o}:$ & 155 & 154 \\
$\mathrm{o}:$ & 168 & 192 \\
$\mathrm{u}:$ & 112 & 122 \\
\hline \hline \multicolumn{3}{|c|}{ SHORT STRESSED VOWELS } \\
\hline $\mathrm{i}$ & 123 & 91 \\
$\varepsilon$ & 154 & 136 \\
$\mathrm{a}$ & 104 & 114 \\
$\mathrm{\rho}$ & 146 & 151 \\
$\mathrm{u}$ & 126 & 88 \\
ə & 122 & 89 \\
\hline \hline \multicolumn{3}{|c|}{ UNSTRESSED VOWELS } \\
\hline $\mathrm{i}$ & 100 & 71 \\
$\mathrm{e}$ & 98 & 143 \\
$\varepsilon$ & 111 & 92 \\
$\mathrm{a}$ & 115 & 113 \\
$\mathrm{\rho}$ & 123 & 103 \\
$\mathrm{o}$ & 123 & 99 \\
$\mathrm{u}$ & 102 & 88 \\
ə & 84 & 67 \\
\hline \hline
\end{tabular}

Table 7: Results of the average vowel duration analysis in the Standard Slovenian language (in miliseconds). The total number of measurements per speaker was 116 (in 96 tokens of the short word set, see Section 2).

The results indicate that:

- The vowels /i,u,ə/ are considerably shorter than the other vowels, regardless of whether they are long stressed, short stressed, or unstressed.

- On average, all stressed vowels are longer than the unstressed ones. The differences, however, are much smaller (if any) for /i/ and /u/, which can be explained by the fact that they are relatively short in all distributions (see Table 7).

- The long stressed vowels are mostly longer than the short stressed ones, except again for /i/ and / $\mathrm{u} /$, where for one speaker the short $/ \mathrm{i}, \mathrm{u} /$ were actually longer on the average than the long ones.

- In comparison with the differences between stressed vs. unstressed vowels, the differences between long and short stressed vowels are much smaller, except for the long stressed /a:/ vs. short stressed /a/ (Table 7).

- On average, the long /e,o/ which, as mentioned above, may also occur in unstressed position, are (for one speaker) considerably longer in stressed syllables. It remains unclear, however, whether these two vowels can be regarded as short in unstressed position.

\section{CONCLUSIONS}

Our measurements have confirmed the traditional observations regarding the essential difference in vowel duration between stressed and unstressed vowels in Standard Slovenian, i.e., that stressed vowels are generally longer than unstressed ones. On the other hand, the traditional subdivision of stressed vowels into long and short, which has already been argued against [6], appears to be questionable with regard to all the vowels that are divided into long and short, with the exception of /a/.

It would definitely be necessary to continue and enlarge our analysis to a more extensive corpus with more speakers, before we could convincingly argue against the traditional theory. Nevertheless, we claim, on the basis of the results obtained both by Srebot-Rejec and our own, that instrumental analysis supports the basic division of vowels into long stressed and short unstressed ones, while the further subdivision of stressed vowels into long and short only seems to be valid for one particular vowel, i.e., the open central vowel /a/.

\section{ACKNOWLEDGEMENTS}

Bojan Petek gratefully acknowledges a postdoctoral scholarship awarded by the Slovenian Science Foundation. His research was also supported in part by the postdoctoral project Z2-7171-0781-95 granted by the Ministry of Science of Slovenia.

\section{REFERENCES}

1. Bajec A., et. al. (Eds.), Slovenski pravopis. DZS, Ljubljana, 1962.

2. Bajec A., Kolarič R., and Rupel M., Slovenska slovnica. DZS, Ljubljana, 1973.

3. Bezlaj F., Oris slovenskega knjižnega izgovora. Znanstveno društvo, Ljubljana, 1939.

4. Ladefoged P., A Course in Phonetics. Second Edition, Harcourt Brace Jovanovich, 1982.

5. Logar T., Slovenska narečja. Mladinska knjiga, Ljubljana, 1993. (a book, a map of the Slovenian dialect system, and 4 audio cassettes of samples)

6. Srebot-Rejec T., Word Accent and Vowel Duration in Standard Slovene: An Acoustic and Linguistic Investigation. Otto Sagner Verlag, 1988.

7. Steenwijk H., The Slovene Dialect of Resia: San Giorgio. Studies in Slavic and General Linguistics, Vol. 18, Rodopi, Amsterdam-Atlanta, GA, 1992.

8. Toporišič J., Glasovna in naglasna podoba slovenskega jezika. Založba Obzorja, Maribor, 1978.

9. Toporišič J., Slovenska slovnica. Založba Obzorja, Maribor, 1984.

10. Trubetzkoy N. S., Grundzüge der Phonologie. Prague, 1939.

11. Zorko Z., Dialectal Portrait of the Drava Valley. Kulturni forum, Maribor, 1995 